\title{
A condição das mulheres no Islã: a questão da igualdade*
}

\begin{abstract}
Aïcha El Hajjami**
\section{Resumo}

No ocidente, o tema da condição das mulheres no Islã está ligado à representação que geralmente se faz do Islã e dos muçulmanos. É uma representação constituída por estereótipos, esquematizações reducionistas e por confusões conceituais. A realidade do Islã e das sociedades muçulmanas possui muito mais nuances e freqüentemente não corresponde às idéias estabelecidas. A condição de inferioridade e precariedade a que está confinada a maior parte das mulheres muçulmanas, revela principalmente a hegemonia de uma mentalidade e de um sistema patriarcal que instrumentaliza sua leitura da religião para legitimar as situações de dominação, de violência e de exclusão em relação às mulheres. Partindo desta constatação, a autora propõe uma outra leitura do Islã e uma reflexão sobre a noção de igualdade no Alcorão e Sunna, na sua relação com o contexto da revelação, as finalidades da Chari'a e as perspectivas de evolução que podem revelar o referencial islâmico. Este trabalho de base é passível de reduzir as distâncias entre os princípios de igualdade entre os sexos inscritos nas convenções internacionais e seu equivalente no Islã.
\end{abstract}

Palavras-chave: Mulheres, Igualdade, Islã.

\footnotetext{
" Recebido para publicação em dezembro de 2007, aceito em abril de 2008 [Tradução: Silvana Ruffier Scarinci].

** Pesquisadora do Centre d'Etudes et de Recherche sur la Femme et la Famille (CERFF), Faculdade de Direito, Universidade Cadi Ayyad, Marrakech.

http://iea:um5s:ac.ma
}

cadernos pagu (30), janeiro-junho de 2008:107-120. 
A condição das mulheres no Islã

Islamic Women's Status: The Question of Equality

\begin{abstract}
The Western idea relative to Islamic women's status is linked to the representations generally held on Islam and Muslim people. These representantions are riddled by esterotypes, reductionist schemas and conceptual confusions. Islam and Muslim societies' reality is much more nuanced and common held ideas do not correspond to it. The inferior status and poverty in which most of Muslim women are confined show the hegemony of a mentality and a patriarchal system that uses its readings of religion in order to legitimate the domination, violence and exclusion of women. Beginning with this idea, the author proposes another reading of Islam and a reflection about the equality notions in the Coran and in the Sunna in the context of revelation, Chari'a objectives and the perspectives of evolution that may reveal the Islamic ways. Working at these roots it may be possible to reduce the distance between the sexes equality principles written at the international conventions and its Islam equivalents.
\end{abstract}

Key Words: Women, Iguality, Islam. 
A condição das mulheres no Islã constitui um dos assuntos mais controversos da atualidade. No ocidente, esse tema é ligado à representação que se faz geralmente do Islã e dos muçulmanos, percebendo-se apenas os aspectos mais negativos $e$ mais espetaculares, amplamente cobertos pela mídia e divulgados sem nenhum discernimento. É uma representação que é constituída de estereótipos e de esquematizações reducionistas $e$ também por confusões conceituais. Ela é ainda mais exacerbada pela homogeneização dos modelos referenciais produzidos pela globalização.

O Islã mantinha, em sua origem, relações de dominação ligando o homem à mulher nas sociedades muçulmanas; ele seria de fato incapaz de levar em consideração as mutações sociais e de ligar-se com a modernidade e os direitos humanos, como é o caso nas sociedades ocidentais onde estes direitos seriam adquiridos definitivamente $e$ as mulheres seriam totalmente liberadas da dominação masculina. Ora, a realidade do Islã e das sociedades muçulmanas, como outras distantes das sociedades ocidentais, possui muito mais nuances e freqüentemente é falsa em relação às idéias estabelecidas.

Se é verdade que a questão de igualdade entre os sexos confronta o referencial islâmico e coloca o mundo muçulmano no tribunal das nações em função das leis de desigualdade que regem as relações sociais entre os sexos, principalmente na esfera privada, não é menos verdade que a condição de inferioridade $e$ de precariedade nas quais estão confinadas a maior parte das mulheres nas sociedades árabe-muçulmanas são oriundas principalmente da hegemonia de uma mentalidade (de um sistema) patriarcal que instrumentaliza sua leitura da religião para legitimar as situações de dominação, de violência e de exclusão em relação às mulheres. É uma leitura baseada numa interpretação restritiva e rígida dos textos corânicos. Assim, muitas regras jurídicas, ditas islâmicas ou qualificadas como chari'a, são construções dos primeiros juristas muçulmanos que, na verdade, realizaram um imenso trabalho de interpretação e de 
A condição das mulheres no Islã

racionalização para adaptar as prescrições corânicas às realidades sociais de sua época. No entanto, muitas vezes, as normas que eles estabeleceram nos domínios familiares refletiam as resistências masculinas às mudanças inauguradas pelas recomendações corânicas. O mesmo ocorreu com os usos e costumes reinantes nas sociedades árabe-muçulmanas freqüentemente apresentadas como se fizessem parte das recomendações islâmicas.

Nos nossos dias, a manutenção de certas leis discriminatórias nas legislações de um grande número de Estados pertencentes à esfera árabe-muçulmana, assim como as ressalvas que acompanham as ratificações das convenções específicas dos direitos das mulheres, impõe uma reflexão sobre a noção de igualdade nos textos sacros do Islã, na sua relação com o contexto da revelação, e as perspectivas de evolução que pode oferecer o referencial islâmico nessa área. Esse trabalho de base é passível de reduzir as distâncias entre o princípio da igualdade dos sexos inscrito nas convenções internacionais, que a maioria dos estados muçulmanos ratificou, e são equivalentes no Islã.

\section{1- Islã e o princípio de igualdade}

A contextualização da revelação do Islã informa sobre o conteúdo revolucionário de sua mensagem quanto às relações sociais de sexo desiguais, existentes na península arábica do sétimo século da era gregoriana. Essas relações, remanescentes da mentalidade patriarcal e da organização tribal e escravagista da época, relegavam as mulheres ao status de mercadoria, fazendo parte do patrimônio de seu marido e de seus herdeiros. Outras práticas desvalorizantes para as mulheres eram costumeiras na sociedade árabe da época, como a poligamia, que não conhecia nenhuma restrição quanto ao número de esposas, o que dependia unicamente da fortuna e status social do homem, ou o repúdio, o casamento forçado, a privação do direito à herança e a escravidão. 
A liberação do ser humano - seja ele homem ou mulher por um lado, de todo tipo de escravidão ou subjugação $e$, por outro, a reconstrução de relações sociais sobre bases igualitárias, são a base do projeto social inaugurado pela mensagem corânica.

O princípio igualitário encontra seus fundamentos no próprio conceito da unicidade de Deus: "Não existe Deus senão Deus", "Nenhum Deus fora de Deus". Essa afirmação constitui uma referência existencial que carrega em si todas as aspirações e/ou reivindicações pela igualdade dos humanos diante de um só Deus, sem nenhum tipo de intermediação. É uma referência liberadora que leva os humanos à sua origem comum:

Humanos, Nós vos criamos de um macho e de uma fêmea. Se de vós fizemos povos e tribos, é graças ao seu conhecimento mútuo. O mais digno aos olhos de Deus é aquele que mais se precavê. ${ }^{1}$

Dessa referência à origem comum da humanidade com relação aos "humanos", sem distinção entre homens, mulheres e raças, derivam-se alguns princípios fundadores das relações sociais construídos pelo Islã:

- A igualdade dos seres humanos supõe a abolição de todo tipo de dominação ou de discriminação através do sexo, raça, cor, riqueza ou classe; cada ser humano é valorizado somente pelo mérito de sua compaixão e de suas boas ações.

- A diversidade dos seres humanos é uma fonte de paz e de enriquecimento, geradora de respeito pelo outro e de não violência contra eles, uma vez que lhes é recomendado estabelecer um reconhecimento mútuo, no sentido intelectual $e$ espiritual do termo.

- Os seres humanos, enquanto representantes de Deus na terra, são iguais em sua responsabilidade pela vida na terra, o respeito pelas outras criaturas e a preservação do ambiente.

${ }^{1}$ Sura XLIX, versículo 13. 
A condição das mulheres no Islã

Essa abordagem igualitária encontra-se nos versículos corânicos e os hadiths relativos às relações específicas no interior do casal. É significativo que a quarta sura intitulada "as Mulheres", que contém a maior parte das prescrições relativas à vida familiar, abre-se com a idéia da origem comum do homem $e$ da mulher que é "alma única" (nafs) ${ }^{2}$, logo aconselhando uma atitude defensiva contra uma agressão eventual sofrida ou temida:

Ó homens! Temei a vosso Senhor, Que vos criou de uma só pessoa e desta criou sua mulher, e de ambos espalhou pela terra numerosos homens e mulheres. E temei Allah, em nome de quem vos solicitais mutuamente, $e$ respeitai os laços consangüíneos. Por certo, Allah, de vós, é Observante. $^{3}$

Um outro versículo descreve os sentimentos de amor e afeição que devem reinar nas relações entre os cônjuges:

Entre Seus desígnios que Ele criou para vós, esposas, a partir de vós próprios ${ }^{4}$, para que ao lado delas vós encontrásseis o apaziguamento; pois Ele está entre elas $e$ vós deveis estabelecer afeição e misericórdia. ${ }^{5}$

2 A palavra (alma) em árabe pode ser empregada no feminino ou masculino. Seu emprego no feminino neste versículo é significativo pela importância do feminino na procriação.

3 N.T.: Tradução do Nobre Alcorão Para a língua portuguesa, Dr. Helmi Nasr [sem lugar nem data de impressão]. www.qurancomplex.org.

$4 \mathrm{Na}$ tradução para o francês deste texto, Jacques Berque traduz o termo "conjoints" por esposos - este termo significa em árabe duplamente o cônjuge masculino ou feminino, sua utilização no plural neste versículo explica o emprego do feminino na continuação do versículo, mas nada indica que a mensagem se dirija aos dois sexos. $\mathrm{O}$ mesmo ocorre cada vez que a mensagem é empregada no masculino no texto do Alcorão, embora em vários versículos, o Alcorão menciona expressamente o masculino e o feminino como no versículo 35 da Sura XXXIII, “...os muçulmanos e as muçulmanas, os fiéis e as fiéis...”.

5 Sura XXX, versículo 21. 
A tradição do profeta foi igualmente portadora de um projeto de transformação social profunda. O profeta iniciou, com suas palavras e sua prática cotidiana, a reconstrução das relações entre os sexos sobre uma base igualitária: "as mulheres são as irmãs uterinas dos homens diante das leis" diz ele num hadith. Ele dizia num outro hadith que percebia no fato do homem aplicar-se às tarefas caseiras, um ato pedagógico de humildade e de reeducação, apropriado para combater a vaidade masculina, $e$ dava ele mesmo o exemplo assumindo diferentes tarefas dos cuidados da casa, reservadas tradicionalmente às mulheres $e$ consideradas como aviltantes para um homem.

Essa abordagem constituía para a época uma reviravolta na distribuição dos papéis estabelecidos socialmente e uma tomada de consciência da separação erigida entre o espaço público e o privado. Aliás, as mulheres muçulmanas da época em que vivia o profeta investiram no espaço público em todos os seus setores: a mesquita, lugar do saber e de tomadas de decisão, o souk, lugar de trocas econômicas e sociais, e participavam da vida política $e$ das guerras para defender a comunidade.

Esses ensinamentos muito ricos em termos de respeito $e$ dignidade para as mulheres não foram, infelizmente, traduzidos pelos diferentes intérpretes de textos sacros nas normas jurídicas dos quais eles foram deduzidos. Ainda pior, algumas prescrições corânicas liberadoras para a época, foram desviadas de suas finalidades e interpretadas com um sentido opressivo. Esse é o caso com a poligamia, com a dissolução do laço conjugal, e da herança, tomando somente estes três exemplos constantemente evocados para criticar a condição das mulheres no Islã.

\section{A poligamia}

O versículo IV/3 relativo à poligamia começa por uma imposição aos tutores de pequenas órfãs, ordenando-lhes que sejam imparciais em relação a elas, e os aconselha, logo a seguir, sem transição, de tomar por esposas outras mulheres, duas, três 
A condição das mulheres no Islã

ou quatro. Isso nos leva a deduzir que esta autorização à poligamia surge com o objetivo de proteger as menores do apetite de seus tutores. Na mesma ocasião, o versículo regulamenta a poligamia limitando o número de esposas legais a quatro; o que na época constituía um progresso numa sociedade que não conhecia nenhum limite quanto ao número de esposas. Mais do que isso, ele condiciona sua prática pelo respeito de "a'dl", a igualdade ou a justiça. O termo utilizado, " $a$ 'dl", significa em árabe uma noção moral mais exigente que a noção de igualdade ou de justiça (Berque, 2002:94).

Visto deste ângulo, a poligamia no Islã é uma prática tolerada sob determinadas condições, e não imposta ou recomendada.

Se temeis não serdes imparciais em relação às órfãs, então casai-vos com aquela que vos agradar entre as mulheres, duas, três ou quatro. Mas se temeis não serdes justo, tomai então somente uma (IV/3).

O simples fato de duvidar em não ser justo ('adil) deve levar o muçulmano a renunciar à poligamia. $\mathrm{O}$ versículo seguinte vai ainda além ao afirmar: "...não podereis ser justo com vossas esposas, mesmo se quiserdes". A dúvida expressa no primeiro versículo, sobre a possibilidade de manter-se imparcial, torna-se neste último uma negociação realista (Berque, 2002:95). Esses versículos são edificantes quanto à intenção do Alcorão em relação à poligamia, uma simples anulação à regra da esposa única. Alguns juristas consideram a própria poligamia como um ato que traz prejuízo à mulher e que não deve ser tolerado senão em situações de necessidade, "dharoura".

É claro que os versículos relativos à poligamia adotam uma marcha evolutiva e progressiva que levam em conta as realidades sociais $e$ as mentalidades da época, afirmando a intenção de restringir a poligamia e abrindo caminho à possibilidade de adaptar a regra jurídica às especificidades de cada sociedade. 
Aïcha El Hajjami

Portanto, no Islã, nada impõe a poligamia. Os muçulmanos, pela via do ijtihâd, podem restringi-la ou mesmo interditá-la.

A finalidade das prescrições legais que regem as diferentes situações do casal ou da família, inscritas no Alcorão ou nos hadiths, não era a de generalizar certas anomalias e ainda menos de institucionalizá-las como é o caso da poligamia ou do repúdio ${ }^{6}$, como elas têm sido, e muitas vezes continuam a ser, praticadas em nossas sociedades, sem levar em conta nenhum dos deveres inerentes.

\section{O divórcio}

O divórcio é considerado pelo Islã como "o ato lícito mais detestável aos olhos de Deus" - dito em um hadith, constitui um remédio para uma situação anormal de um casal para o qual a vida em comum se tornaria insuportável. "Se, não alcançando um entendimento, os dois esposos preferem se separar, Deus, em sua bondade, lhes dará a cada um, melhor destino". ${ }^{7}$ A dissolução do laço conjugal é um direito que pertence aos dois cônjuges. Quando o marido divorcia-se de sua mulher, ele deve oferecer uma compensação em troca do prejuízo assim sofrido por ela. Por outro lado, a mulher tem o direito de pedir o divórcio e de obtê-lo em caso de prejuízo; na ausência de prejuízo, ela pode obtê-lo através de compensação oferecida ao seu esposo. Nada no Alcorão autoriza um marido a manter à força sua esposa se ela deseja pôr fim à união conjugal. Os hadiths são ainda mais edificantes sobre este assunto.

\footnotetext{
6 O termo "repúdio" é uma tradução inapropriada, do nosso ponto de vista, do termo árabe "talâq". Este último não contém nenhuma conotação pejorativa, contrariamente ao termo "repúdio". Ele se aproxima mais do termo "liberação". Isso não impede que, na realidade, freqüentemente a dissolução do laço conjugal exercido pelo marido de maneira unilateral tome a forma humilhante $e$ desprezível de uma rejeição, de um repúdio.

7 IV, versículo 130.
} 
A condição das mulheres no Islã

Os versículos relativos ao divórcio contêm, sem exceção, recomendações ao homem - que na realidade social da época, detinha o poder do "repúdio" - de não causar prejuízo à mulher,

...ou bem as conservai de acordo com as conveniências, ou bem as liberai de acordo com as mesmas conveniências. Não as retenhais para lhes prejudicar, por pura transgressão: quem assim o fizer seria injusto consigo mesmo $^{8}$, ...não levantai nenhuma dificuldade contra seu (o cônjuge divorciado) novo casamento com um novo marido, se eles puseram-se de acordo segundo as conveniências. Que isto edifique quem quer que seja dentre vós que crê em Deus e no Dia Final. Agir desta maneira será para vós mais correto e mais puro. ${ }^{9}$

\section{A herança}

O direito sucessório no Islã parte do princípio geral que vê a riqueza como propriedade divina antes de tudo, a qual não deveria ser acumulada como um tesouro, mas dividida igualitariamente entre aqueles que têm direito.

A herança no Islã abarca a herança por obrigação (al fardh) subdividida em seis categorias nas quais as partes são definidas da seguinte maneira: os dois terços, a metade, o terço, o quarto, o sexto e o oitavo, e a herança do que sobra uma vez deduzias as partes obrigatórias (al ta'sib).

Muitas vezes censurou-se o Islã por ter privilegiado em termos de herança o homem ao contrário da mulher, ao conceder ao primeiro o dobro da parte concedida à última - ora, uma análise aprofundada do direito sucessório mostra que essa regra não é aplicada senão em 16,33\% dos casos, e são todos os casos nos quais o homem tem a obrigação de cuidar da família, sabendo-se que a mulher é livre de manter seus bens e não é

\footnotetext{
8 II, versículo 231.
}

9 II, versículo 232. 
obrigada a participar das obrigações da casa, mesmo quando ela é rica. No outros casos, ou ela recebe a mesma parte que o homem, ou ela herda uma parte maior - ocorre inclusive que ela o priva totalmente de sua herança. Pois a mulher herda baseado na herança por obrigação em $90 \%$ dos casos contra $13 \%$ no caso dos homens. Em conseqüência disso, na maioria dos casos, a mulher tem prioridade em relação ao homem e mais possibilidades de ter herança do que ele, pois o homem não recebe herança senão após a divisão da herança obrigatória.

Instituir essas regras na sociedade árabe da época, quando a mulher não tinha direito à herança, constitui-se por si só numa revolução social.

\section{2 - O papel do Ijtihâd na evolução da legislação muçulmana}

A produção da maioria das regras e disposições jurídicas relativas ao direito da família deu-se, no correr dos três primeiros séculos do Islã, em função das realidades sociais da época. Tratava-se de regulamentar as novas situações que não eram regidas pelos textos do Alcorão e dos hadiths. Essa operação tornou-se possível graças ao Ijtihâd, um método de interpretação de textos sagrados, elaborado pelos ulamâ (os teólogos e os sábios) do Islã, e encorajado pelo próprio profeta durante sua vida. O Alcorão contem igualmente constantes apelos à utilização da razão e da reflexão.

O Ijtihâd é um elemento que vai além da leitura literal dos textos sagrados, sem, no entanto, destituí-los de sua operacionalidade contemporânea e seu valor intrínseco. É uma busca do sentido que tende a decifrar a intenção divina "al maqâssid", que é a procura do bem comum, numa preocupação pelo equilíbrio e imparcialidade.

Esse método deu lugar ao nascimento da teoria do "maqâssid al-sharî 'a" que o grande jurista andaluz Al-Shâtibî teve o mérito de desenvolver, a partir do princípio do bem comum "almassâlih al-mursala". Este consiste em esclarecer as qualificações 
A condição das mulheres no Islã

legais "istinbât al-ahkâm", não a partir de uma exegese literal e léxica dos textos, mas buscando sua razão essencial "al- illa" (o princípio de motivação) e sua finalidade, que não podem $e$ não devem se remeter senão ao bem comum "maslaha". O objetivo é de adaptar a regra jurídica/hukm às exigências das circunstâncias levando em consideração, sobretudo o sentido latente dos textos que exprimiriam melhor a intenção divina. ${ }^{10}$

A suspensão da prática do ijtihâd no início do século IV da hégira ${ }^{11}$ colocou um ponto final no espírito de inovação que animava os primeiros juristas muçulmanos. A partir desse momento, os adeptos de cada escola erigiram a produção jurídica dos líderes fundadores sobre textos sacros de modo que não sofressem nenhum enfraquecimento ou desgaste do tempo, uma vez que a jurisprudência dos primeiros teólogos muçulmanos respondia às realidades e contextos sociais de sua época. Esses teólogos possuíam a sabedoria de sempre relativizar seus julgamentos e não hesitavam em revisá-los em função das novas realidades ou de argumentos mais convincentes.

As mulheres foram as principais vítimas da interrupção da prática do Ijtihâd na medida em que os direitos que lhe eram reconhecidos no início da era muçulmana foram renegados com o passar do tempo em nome de uma leitura restritiva dos textos sacros. Usos e costumes desfavoráveis à emancipação das mulheres foram sacralizados e erigidos com regras imutáveis. De maneira geral, o figh relativo à condição das mulheres foi muito mais o reflexo de uma mentalidade patriarcal e tribal que uma aplicação restrita de valores de igualdade, de dignidade e de justiça preconizados pelo Alcorão e o Sunna.

\footnotetext{
${ }^{10}$ Para uma compreensão aprofundada do conceito do ijtihâd, consultar, entre outros, as obras de Al-Shâtibî (Abû Isshaâq). Nascido em Granada no começo do século XIV, morto em 1388 (790 da hégira). Ele foi o precursor da ciência de "al maqâssid", especialmente em seu livro de 1975; Achour, 1988; Al-Anssari, 2003.

${ }^{11}$ N.T.: hégira significa "era maometana", que se inicia com a fuga de Maomé de Meca para Medina, em 622 na nossa era.
} 
Isso provoca o engajamento das sociedades muçulmanas de hoje a procederem à uma releitura do corpus jurídico islâmico à luz de preceitos fundadores do Islã, de forma a permitir a este último de tornar-se hoje um vetor de valores universais dos direitos humanos como fora no tempo da Revelação.

Nas sociedades nas quais o referencial islâmico representa um fator central, somente o ijtihâd permite uma releitura de textos sacros dentro de uma perspectiva de melhoria da condição jurídica das mulheres. ${ }^{12}$ Da mesma forma, seria também necessário fazer com que as legislações que regem os domínios da família nos países muçulmanos evoluam, em vista de adaptá-las às realidades contemporâneas e às aspirações legítimas das mulheres muçulmanas à uma cidadania igual a dos homens.

O exemplo marroquino da reforma do direito da família constitui inegavelmente um exemplo do exercício de um Ijtihâd inovador que foi feito com respeito aos princípios de igualdade $e$ de justiça preconizados pelos textos sacros.

A adoção do novo Código da Família marroquina de fevereiro de 2004 constitui um avanço considerável na melhoria da condição jurídica das mulheres.

O Novo Código da Família ${ }^{13}$ rompeu com essa visão degradante da mulher, ao adotar disposições que se dirigem à instauração do equilíbrio familiar e à dignidade de seus membros.

12 Sobre este assunto, ver nossa conferência: "L'ijtihâd na questão feminina, fundamentos e perspectivas", apresentada na série de palestras do mês de ramadã (N.T.: o nono mês do ano muçulmano, sagrado, quando é prescrito o jejum entre o amanhecer e o pôr do sol) no palácio Real de Rabat, em 27 outubro de 2004, e publicado pelo ministério de assuntos islâmicos, Al-dourouss al-hassania, 2004:75-91 (em árabe).

${ }^{13} \mathrm{O}$ projeto do Novo Código foi preparado por uma comissão composta por teólogos juristas, "ulamâ", aos quais se associaram especialistas de diferentes áreas no que diz respeito ao direito da família, depois de ter sido recolhido as proposições advindas de representantes da sociedade civil. A reforma foi homologada por votação unânime do projeto pelas duas câmaras do parlamento em 16 de janeiro de 2003 e por sua publicação no Diário Oficial, em 4 de fevereiro de 2004. 
A condição das mulheres no Islã

Este texto, de inspiração igualitária, baseia-se numa leitura mais aberta dos textos sacros, em relação com a realidade da sociedade marroquina atual $e$ suas exigências, sempre em conformidade com os valores universais de igualdade $e$ de dignidade inscritos nas convenções internacionais que o Marrocos assinou e ratificou. Assim, o novo Código suprime a tutela matrimonial para as mulheres maiores de idade, fixa a mesma idade legal do casamento para os dois sexos (18 anos), coloca a família sob a responsabilidade conjunta dos esposos, instaura condições severas em relação à poligamia, que tornam seu uso quase impossível, e concede os direitos equivalentes aos dois cônjuges nos diferentes modos de dissolução do laço conjugal, sempre os submetendo ao controle do juiz.

\section{Referências bibliográficas}

AcHour, Tahar Ben. Maqâssid al-sharî‘a al islâmia. $3^{e}$ éd. Société tunisienne de distribution, 1988.

Al-AnsSARI, F. Al-moustalah al-ùsûli 'inda Al-Shâtibî. Casablanca, Edit.al-Najâh al-Jadida, 2003.

AL-SHÂTiBî, Abû Isshaâq. Al-mouâfaqâte fi ùssoul al-sharî'a. $2^{e}$ éd. Bayrût, Edição Dar al-ma'rifa, Tomo 4, 1975.

BERQUE, V.J. L'éternel féminin est rendu à sa dignité. In: Le Coran, essai de traduction. Paris, Edition Albin Michel, 2002. 